\title{
MUSCLE POWER AND VELOCITY DURING TRUNK ROTATIONS AFTER 6 WEEKS OF TRAINING IN ICE-HOCKEY PLAYERS
}

\author{
Oliver Poór, Dominik Glevaňák, Erika Zemková
}

\author{
Department of Sport Kinantropology, Faculty of Physical Education and Sport, \\ Comenius University in Bratislava, Slovakia
}

\begin{abstract}
Summary: The study evaluates changes of muscle power and velocity during trunk rotations in icehockey players after six weeks of training in competition period. A group of 15 ice-hockey players performed 2 trunk rotations to each direction in a standing position with barbell of $6,10,12,16,20,22$, $26 \mathrm{~kg}$ placed on the shoulders. Basic biomechanical parameters during the movement were monitored using the FiTRO Torso Dyne system. Results showed that mean velocity in acceleration phase of trunk rotation significantly increased after 6 weeks of training at $6 \mathrm{~kg}$ (from 259 to $282.6 \mathrm{deg} / \mathrm{s}, \mathrm{p}=0.003$ ) and $12 \mathrm{~kg}$ (from 218.8 to $244.1 \mathrm{deg} / \mathrm{s} \mathrm{p}=0.004$ ). However, its values did not changed significantly during rotations with $10,16,20,22$ and $26 \mathrm{~kg}$. Mean power of trunk rotation did not changed significantly with any of used weight. These findings indicate that there are only small changes in muscle power in competition period of ice hockey-players.
\end{abstract}

Key words: competition period, rotational power, trunk muscles

DOI 10.1515/afepuc-2017-0009

(C) Acta Facultatis Educationis Physicae Universitatis Comenianae 


\section{Introduction}

Core spinal muscles are related to trunk stability and assume the main role of stabilizing the spine during daily activities. Primary the core-stregthening was an important part of rehabilitation and muscle injury prevention. Therefore is no surprise that corestrengthening exercises have also become a part of amateur and professional sportsmen training (Hibbs et al. 2008; Kibler et al. 2006). Core exercises are also used as an important part in long term conditioning, to gain maximal performance in most sports (Lehman 2006).

Traditionally used power measurements incorporating the lower limbs are often linear in nature. There is less known about the involvement of the upper extremities and the trunk musculature. Since the core is central to almost all sports activities, control of core strength, balance and motion should optimize upper and lower extremity function (Akuthota \& Nadler 2004). However, most core assessments are focused on isometric muscular endurance with long tension times and low loads (Ellenbecker \& Roetert 2004; Kumar et al. 1996; Lindsay \& Horton 2006; Müller et al. 2012; Engel et al. 2013). Given that most athletic upper body power generation involves high levels of neuromuscular activation of a rotational nature, it is important to assess athletic ability that replicates as closely as possible the rotational activity of an athlete (Talukdar et al. 2015). Effective execution of movement requires also strength and power of trunk muscles.These muscles (erector spinae, abdominal oblique, and rectus abdominis) are particularly active during the acceleration phase of trunk rotations (Bae 2012).

Most of the testing methods evaluating the efficiency of training programs for improving core stability are insufficient. Rather, they are based on the biomechanical analysis of technique, the experience of conditioning specialists or cross-sectional training evidence. In addition, low reliability and sensitivity of current diagnostic methods evaluating the strength of lower back muscles limits their practical application. In order to provide testing conditions specific to demands imposed by most sports, one can use a system that allows monitoring of basic biomechanical parameters during rotational movement of the trunk. Presumably, the test adapted from the wood chop exercise may provide conditions similar to those imposed in many sports involving trunk rotation such as baseball, golf, karate, and so forth (Zemková 2015). The study of Andre et al. (2012) determined the test-retest reliability of the kinetic rotational characteristics of the pulley trainer when performing a rotational exercise of the axial skeleton in the transverse plane. The authors found that a pulley system and an external dynamometer can be used together as a reliable research tool to assess rotational power. However, this does not guarantee that power measured during a standing cable wood chop 
exercise will provide similar reliability. Power in the acceleration phase can be used as a parameter of functional assessment of trunk muscles (Zemková et al. 2014) in athletes of different specializations as well as its changes during the training.

There was alternative to use inertial dynamometer allowing assessment of muscle power during trunk rotations. Using such a system it was distinguished that mean power and eamong group of athletes such as karate, ice-hockey, tennis, golf, ballroom dancing, rock \& roll dancing, judo, wrestling, canoeing, rowing, weightlifting, and bodybuilding (Zemková et al. 2013, 2014). Though the system was found to be sensitive in discrimination of groups of athletes of various sport specializations, it is not known whether it can reveal slight changes in muscle power and velocity during trunk rotations in preparation and/or competition period in well-trained athletes. Therefore the aim of the study was to evaluate the effect of 6-week training of ice-hockey players in competition period on muscle power and velocity during trunk rotations.

\section{Methods}

Fifteen ice-hockey players $(19.9 \pm 1.1$ years, height $182.7 \pm 4.6 \mathrm{~cm}$, weight $81.2 \pm 5.7$ $\mathrm{kg}$ ) competiting in Slovak Cup participated in this study. They were at good health and free of any injuries 6 months before and during the study. Each players was on the competition roster of his team.

Players were tested in the competition period prior to and after 6 weeks of training. All tests were performed indoor, in Poprad Ice-hockey Stadium Gym. Before the testing, all participants completed an individual warm-up consisting mostly of cycling and dynamic stretching. Each participant performed 2 trunk rotations to each direction (either from right to left or from left to right) in a standing position with barbell of $6,10,12,16,20,22$, and $26 \mathrm{~kg}$ placed on the shoulders (Fig. 1). Participants were instructed to perform trunk rotations with maximal effort during the acceleration phase of movement. 


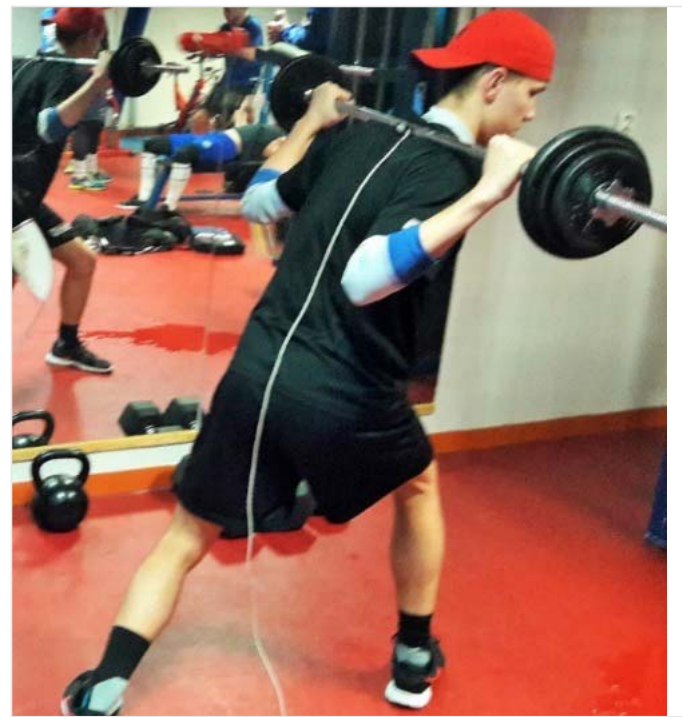

Figure 1

Assesment of power and velocity of the trunk rotation in a standing position with barbell placed on the shoulders

The FiTRO Torso Dyne (Fig. 2) was used to monitor basic biomechanical parameters of the movement. The system consists of an inertial measurement unit in a small box with an integrated USB interface and software. While inserted on the barbell axis, the sensor unit registers instant angular of rotation movement. Calculations of force and power are based on the Newton's second law of mechanics. Force produced to accelerate and decelerate a rotation movement is obtained as a product of barbell mass and acceleration of its center of gravity (CoG). Angular acceleration is obtained by derivation of angular velocity. For the transformation of angular velocity and acceleration into their real values, a rotation radius (distance between rotation axis and barbell mass $\mathrm{CoG}$ ) is used. Power is calculated as a product of force and velocity.

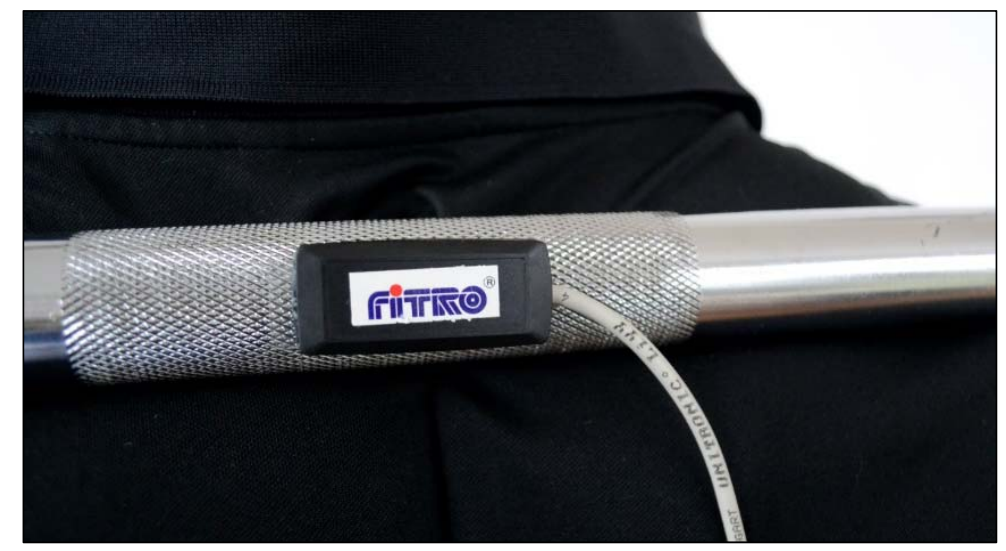

Figure 2

FiTRO Torso Dyne sensor unit placed on the barbell axis 
All statistical procedures were conducted using IBM SPSS Statistics 22.0. Wilcoxon ttest was used to determine significance in mean power and velocity before and after the training. P-value $<.05$ was defined as a statistically significant.

\section{Results}

Mean velocity of trunk rotation significantly increased after 6 weeks of the training at $6 \mathrm{~kg}(\mathrm{p}=0.003)$ and $12 \mathrm{~kg}(\mathrm{p}=0.004)$. However, its values did not changed significantly during rotations with $10 \mathrm{~kg}(\mathrm{p}=0.224), 16 \mathrm{~kg}(\mathrm{p}=0.049), 20 \mathrm{~kg}(\mathrm{p}=0.037), 22 \mathrm{~kg}(\mathrm{p}=$ $0.032)$ and $26 \mathrm{~kg}(\mathrm{p}=0.788)$ (Fig. 3).

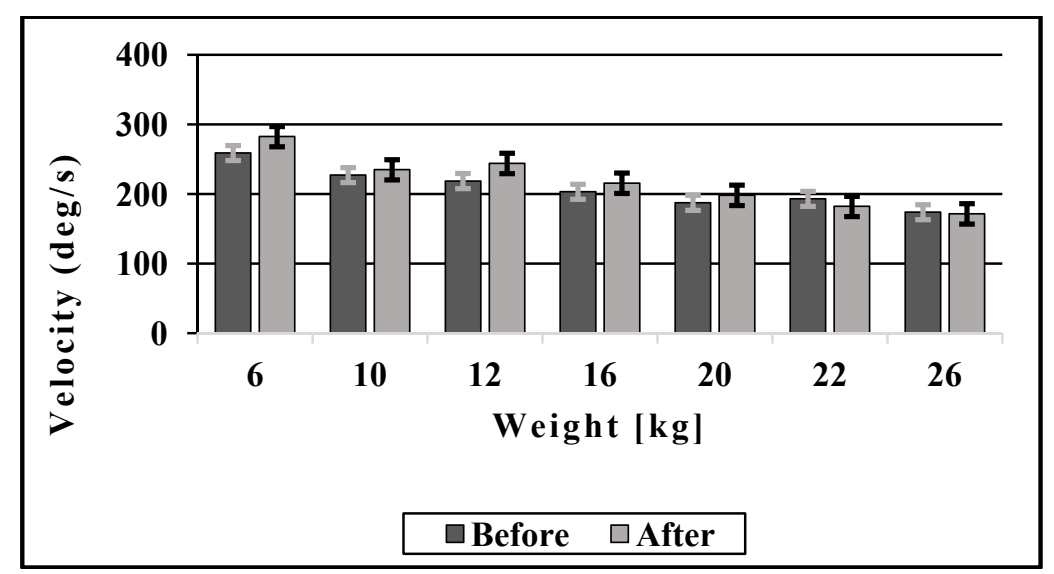

Figure 3

Mean velocity in the acceleration phase of trunk rotation before and after 6-week training in icehockey players

Mean power of trunk rotation did not changed significantly with any of used weight, i.e. $6 \mathrm{~kg}(\mathrm{p}=0.45), 10 \mathrm{~kg}(\mathrm{p}=0.886), 12 \mathrm{~kg}(\mathrm{p}=0.153), 16 \mathrm{~kg}(\mathrm{p}=0.435), 20 \mathrm{~kg}(\mathrm{p}=0.683)$, $22 \mathrm{~kg}(\mathrm{p}=0.538)$ and $26 \mathrm{~kg}(\mathrm{p}=0.771)$ after six weeks of the training in competition period of ice-hockey players (Fig. 4). 


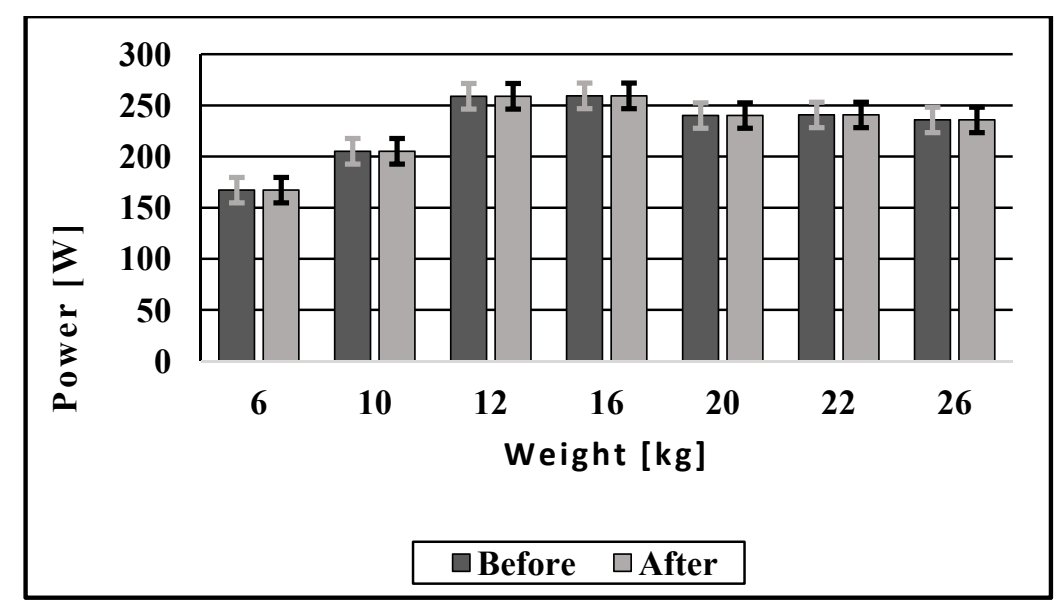

Figure 4

Mean power in the acceleration phase of trunk rotation before and after 6 weeks of the training in icehockey players

\section{Discussion}

Velocity of trunk rotations increased significantly after six weeks of the training with lower weights (6 and $12 \mathrm{~kg}$ ) whereas its values did not changed significantly when higher weights were used $(16,20,22$ and $26 \mathrm{~kg})$. This may be due to of using lower weights in competition period trainings while focusing on acceleration of the movement. However, mean power of the rotation movement did not changed significantly. This may be ascribed to the fact that in the competiton period ice-hockey coaches are focused on game preparation and winning matches. For this reason the condition capacity is usually slowly decreasing with ongoing season. On the other hand, in pre-season preparation is aim to gain high capacity in condition what is essencial for every basic on-ice skill. Exercises during preparation period are mostly performed with higher weights to gain higher muscle strength.

Our previous study showed that mean velocity of rotational movement of the trunk significantly increased after 6 weeks of training in preparation period of canoeists at all weights used (from 6 to $26 \mathrm{~kg}$ ). Mean power during trunk rotations also increased significantly with these weights used except the weight of $6 \mathrm{~kg}$ (Poór \& Zemková 2017). The purpose of this period is to gain high capacity in condition what is essencial for every paddle shot. Exercises during preparation period of canoeists are mostly performed with higher weights to gain higher muscle strength while also aimed at improvement of movement velocity, similarly to ice-hokey.

To our best knowledge, only these two studies evaluated changes in muscle power during trunk rotations in competitive athletes (ice-hockey players and canoeists). Previous studies mainly compared rotational power in athletes of various specializations. Interestingly, 
mean power in the acceleration phase of trunk rotations with weights of $6,10,12,16,20$, and $22 \mathrm{~kg}$ was higher in boxers and thai boxers as compared to our group of ice-hockey players (Obžera 2014). Similarly, greater values of mean power were also observed in wrestlers than ice-hockey players in the present study (Skovay 2015). Further studies are needed to evaluate the changes in rotational power after different training periods in these groups of athletes.

\section{Conclusion}

Mean velocity significantly increased after 6 weeks of training at $6 \mathrm{~kg}$ and $12 \mathrm{~kg}$, whereas its values did not changed significantly during rotations with higher weights $(16,20$, 22 and $26 \mathrm{~kg}$ ). However, there were no significant changes in mean power of trunk rotation after six weeks of training in competition period of ice-hockey players. These findings reflect specificity of the training in competition period.

\section{Acknowledgements}

This work was supported by the Slovak Research and Development Agency under the contract No. APW-15-0704.

\section{References}

1. AKUTHOTA, V. \& S. F. NADLER, 2004. Core strengthening. In: Archives of Physical Medicine and Rehabilitation Journal. 85(Suppl. 1), 86-92. ISSN 0003-9993.

2. ANDRE, M. J. et al., 2012. A reliable method for assessing rotational power. In: The Journal of Strength and Conditioning Research. 26(3): 720-724. ISSN 1064-8011.

3. BAE, J. H. et al., 2012. Asymmetry of the isokinetic trunk rotation strength of korean male professional golf players. In: Annals of Rehabilitation Medicine. 36(6): 821-827. ISSN 2234-0653.

4. ELLENBECKER, T. S. \& E. P. ROETERT, 2004. An isokinetic profile of trunk rotation strength in elite tennis players. In: Medicine \& Science in Sports \& Exercise. 36(11): 1959-1963. ISSN 0195-9131.

5. HIBBS, A. E., K. G. THOMPSON, D. FRENCH, A. WRIGLEY \& I. SPEARS, 2008. Optimizing performance by improving core stability and core strength. In: Sports Medicine. 38(12): 995-1008. ISSN 0112-1642.

6. KIBLER, W. B., J. PRESS \& A. SCIASCIA, 2006. The role of core stability in athletic function. In: Medicine \& Science in Sports \& Exercise. 36(3): 189-198. ISSN 0112-1642. 
7. KUMAR, S., Y. NARAYAN \& M. ZEDKA, 1996. An electromyographic study of unresisted trunk rotation with normal velocity among healthy subjects. In: Spine. 21(13): 1500-1512. ISSN 0362-2436.

8. LEHMAN, G. J., 2006. Resistance training for performance and injury prevention in golf. In: The Journal of the Canadian Chiropractic Association. 50(1): 27-42. ISSN 17156181.

9. LINDSAY, D. \& J. F. HORTON, 2006. Trunk rotation strength and endurance in healthy normals and elite male golfers with and without low back pain. In: North American Journal of Sports Physical Therapy. 1(2): 80-89. ISSN 1558-6170.

10. MÜLLER, S., J. STOLL, J. MUELLER \& F. MAYER, 2012. Validity of isokinetic trunk measurements with respect to healthy adults, athletes and low back pain patients. In: Isokinetics and Exercise Science. 20(4): 255-266. ISSN 0959-3020.

11. OBŽERA, P., 2014. Svalový výkon pri rotáciách trupu u športovcov úpolových športov. Bratislava. Comenius University in Bratislava. Diploma Thesis. Faculty of Physical Education and Sports, Department of Sports Kinanthropology.

12. POÓR, O. \& E. ZEMKOVÁ, 2017. Muscle power and velocity during trunk rotations after 6 weeks of training in canoeists. In: Telesná výchova a šport (in review). ISSN $1335-2245$.

13. SKOVAY, L., 2015. Svalový výkon pri rotačnom pohybe trupu thajských boxeristov a zápasníkov. Bratislava. Comenius University in Bratislava. Diploma Thesis. Faculty of Physical Education and Sports, Department of Sports Kinanthropology.

14. TALUKDAR, K., J. CRONIN, J. ZOIS \& A. P. SHARP, 2015. The role of rotational mobility and power on throwing velocity. In: Journal of Strength and Conditioning Research. 29(4): 905-911. ISSN 1064-8011.

15. ENGEL, T., C. HOLZAPFEL, S. KOPINSKI, S. MUELlER \& F. MAYER, 2013. Reliability of isokinetic trunk measurements with and without perturbation in young athletes. In: EFSMA $8^{\text {th }}$ European Sports Medicine Congress, Strasbourg. European Journal of Sports Medicine. 1(Suppl. 1), 167. ISSN 1792-4979.

16. ZEMKOVÁ, E., M. JELEN, G. OLLÉ \& D. HAMAR, 2013. Mean velocity of trunk rotation discriminates athletes with different sport-related demands. In: EFSMA 8th European Sports Medicine Congress, Strasbourg. European Journal of Sports Medicine. 1(Suppl. 1), 216. ISSN 1792-4979.

17. ZEMKOVÁ, E., M. JELEN, G. OLLÉ \& D. HAMAR, 2014. Mean power and velocity in acceleration phase of trunk rotation in athletes with different explosive force 
production capacity. In: $19^{\text {th }}$ Annual Congress of the European College of Sport Science. European College of Sport Science Amsterdam: University Amsterdam. ISBN 78-94-622-8477-7.

18. ZEMKOVÁ, E., 2015. Assessment of core performance in athletes. In: Od výskumu $k$ praxi [CD-ROM]. Bratislava: STU. ISBN 978-80-227-4484-3. 